\title{
Community Transmission of SARS-CoV-2 by Surfaces: Risks and Risk Reduction Strategies
}

\author{
Ana K. Pitol* and Timothy R. Julian
}

Cite This: Environ. Sci. Technol. Lett. 2021, 8, 263-269

Read Online

ABSTRACT: SARS-CoV-2, the virus responsible for the COVID-19 pandemic, is perceived to be primarily transmitted via person-to-person contact through droplets produced while talking, coughing, and sneezing. Transmission may also occur through other routes, including contaminated surfaces; nevertheless, the role that surfaces have on the spread of the disease remains contested. Here, we use the Quantitative Microbial Risk Assessment framework to examine the risks of community transmission of SARS-CoV-2 through surfaces and to evaluate the effectiveness of hand and surface disinfection as potential interventions. Using conservative assumptions on input parameters of the model (e.g., dose-response relationship, ratio of genome copies to infective virus), the average of the median

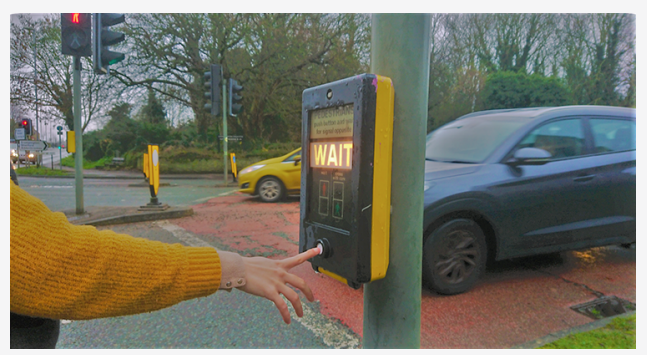
risks for single hand-to-surface contact followed by hand-to-face contact range from $1.6 \times 10^{-4}$ to $5.6 \times 10^{-9}$ for modeled prevalence rates of $0.2 \%-5 \%$. For observed prevalence rates $(0.2 \%, 1 \%)$, this corresponds to a low risk of infection $\left(<10^{-6}\right)$. Hand disinfection substantially reduces risks of transmission independently of the disease's prevalence and contact frequency. In contrast, the effectiveness of surface disinfection is highly dependent on the prevalence and the frequency of contacts. The work supports the current perception that contaminated surfaces are not a primary mode of transmission of SARS-CoV-2 and affirms the benefits of making hand disinfectants widely available.

\section{INTRODUCTION}

SARS-CoV-2, the virus responsible for the COVID-19 pandemic, is transmitted primarily via person-to-person pathways such as prolonged exposures to respiratory droplets produced while talking, coughing, and sneezing. ${ }^{1,2}$ On the basis of the assumption of respiratory-droplet transmission, infection control recommendations include maintaining social/physical distances, wearing masks, case isolation, contact tracing, and quarantine. ${ }^{3}$ Due to the possibility of transmission through other routes, including airborne and surface-mediated transmission, the WHO recommends taking airborne precautions for particular settings where aerosols are generated and emphasizes the importance of hand hygiene. ${ }^{2}$ Nevertheless, the role that airborne and surface-mediated transmission have on the spread of the disease remains contested. ${ }^{1,2,4-7}$

Indirect transmission via fomites (contaminated surfaces) contributes to the spread of common respiratory pathogens, ${ }^{8-10}$ and evidence to date suggests fomite transmission is possible for SARS-CoV-2. People infected with SARS-CoV-2 shed the virus into the environment, as evidenced by extensive SARS-CoV-2 RNA detected on surfaces in cruise ships, hospitals, and public spaces in urban areas such as bus stations and public squares. ${ }^{11-15}$ Infective coronavirus persists in the environment, with experimental evidence of persistence on surfaces ranging from $3 \mathrm{~h}$ to 28 days, depending on environmental factors such as surface material and temperature. ${ }^{16-18}$ Viruses readily transfer from contaminated surfaces to the hand upon contact ${ }^{19-21}$ and from hands to the mucous membranes on the face. ${ }^{21-23}$ People touch their faces frequently, with studies reporting average hand-to-face contacts ranging from 16 to 37 times an hour. ${ }^{24-27}$ Taken together, this suggests surface contamination could pose a risk for indirect SARS-CoV-2 transmission, similar to other respiratory viruses. ${ }^{8}$

Despite the potential importance of indirect transmission, it is difficult to estimate its role relative to direct transmission. Quantitative Microbial Risk Assessment (QMRA) provides a framework for understanding health risks from indirect transmission and provides insights into potential impacts of infection control recommendations. Mechanistic models of transmission events within the context of QMRA frameworks have been used to identify risks for a number of scenarios including children playing with fomites, ${ }^{28}$ sanitation workers collecting and processing urine for nutrient recovery, ${ }^{29}$ and people sharing a houseboat. ${ }^{30}$ Within the context of the current COVID-19 pandemic, QMRA has been adapted to evaluate and compare transmission risks for MERS-CoV and SARS-CoV-2 through droplets, aerosolized particles, and

Received: December 11, 2020

Revised: December 23, 2020

Accepted: December 23, 2020

Published: January 6, 2021

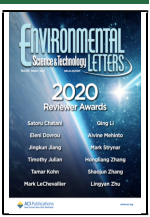


doffing personal protective equipment in hospitals ${ }^{31-33}$ and to evaluate the effectiveness of masks at reducing the risk of SARS-CoV-2 infection. ${ }^{34}$

In this study, two mechanistic models of indirect transmission within the QMRA framework are used to estimate the risk of infection for SARS-CoV-2 in community settings and inform guidance on potential intervention strategies. Specifically, a model is developed to estimate the risk of infection for single contacts with contaminated surfaces, with the concentrations of SARS-CoV-2 RNA on the surfaces informed by literature reporting investigations of surface contamination in public spaces (bus stations, gas stations, stores, playgrounds). A second model is used to estimate risks from surfacemediated community transmission as a function of the prevalence of COVID-19 cases in the community and to test the efficacy of feasible intervention strategies of hand disinfection and surface disinfection.

\section{MATERIALS AND METHODS}

Model 1. Risks from Contaminated Surfaces. A stochastic-mechanistic model was developed to estimate the infection risk for a single hand-to-surface contact followed by hand-to-face contact (Figure S1). The concentration of SARSCoV-2 RNA on public surfaces [gene copy number $(\mathrm{gc}) \mathrm{cm}^{-2}$ ] was obtained from the literature. ${ }^{13,15}$ The risks were estimated based on the reported concentrations measured on the subset of samples with detectable and quantifiable SARS-CoV-2 RNA. Conversion of SARS-CoV-2 RNA to infective virus was assumed to follow a uniform distribution with range between 100 and 1000 (gc per infective virus, with infective virus measured using Plaque Forming Units (PFU)). The gc:PFU ratio is based on the sparsely available information on SARSCoV-2 found in the literature; ${ }^{18,35,36}$ data from SARS-CoV (ratio of $\sim 300$ gc per PFU), ${ }^{37}$ data from enveloped respiratory RNA viruses ${ }^{38}$ (seasonal influenza $\mathrm{A}(\mathrm{H} 1 \mathrm{~N} 1), \mathrm{A}(\mathrm{H} 3 \mathrm{~N} 2)$, and influenza $B$ have mean ratios of 708,547 , and 185 gene copies per $\mathrm{TCID}_{50}$, respectively) and a ratio of 0.7 to convert $\mathrm{TCID}_{50}$ to PFU. ${ }^{39}$ To account for the difference in the decay rate of the infectious virus on the surface compared with the decay rate of viral RNA, we used a uniform distribution from 1 to 50, informed by data on influenza's persistence on surfaces. ${ }^{40}$ The transfer of the virus from surface-to-hand and from hand-tomucous membranes was assumed to be proportional to the concentration of the virus on the surface and the transfer efficiency of the virus at both interfaces. ${ }^{41}$ The probability of infection for a given dose $\left(P_{\text {inf }}\right)$ was estimated using an exponential dose-response model

$$
P_{\text {inf }}=1-\mathrm{e}^{-k D}
$$

where $D[\mathrm{PFU}]$ is the infectious dose and $k=2.46 \times 10^{-3}$ $[\mathrm{PFU}]^{-1}$ is the dose-response parameter. ${ }^{42}$ This model is based on the pooled data of studies of SARS-CoV ${ }^{43}$ and Murine hepatitis virus (MHV-1 $)^{44}$ infection in mice. The upper bounds of the dose-response curve are consistent with the infectivity of two different variants of SARS-CoV-2 in mice, hamsters, and ferrets, which showed $100 \%$ infectivity at a dose of $10^{5} \mathrm{TCID}_{50}{ }^{45}$ Monte Carlo simulations were used to incorporate the uncertainty and variability of the input parameters. The model was simulated 50,000 times. Results are presented as the median risk values with 5th and 95th percentiles. The equations used, the probability distributions for the input parameters, and a diagram of the model can be found in the Supporting Information (Figures S1-S3, Table S1).

Model 2. Risks from Surface-Mediated Community Transmission. Contamination of SARS-CoV-2 on surfaces in public spaces (e.g., traffic light buttons, train buttons) was modeled as a function of disease prevalence in the community and frequency of contact with the surface. Estimates obtained in the model describe the probability of infection for people contacting the surface across a period of 7 days. In the model, surface inoculation happens when infected individuals use their hand to cover their mouth while coughing and subsequently touch a surface. Viral loads $\left(\mathrm{gc} \mathrm{mL}^{-1}\right)$ in the saliva or sputum of symptomatic COVID-19 patients within the first 14 days of symptom onset were used as input to the model. ${ }^{36,46-48}$ The concentrations of SARS-CoV-2 in saliva and sputum samples measured in genome copies ${ }^{36,46-48}$ align with concentrations of samples measured in $\mathrm{TCID}_{50}{ }^{35}$ once they are adjusted by the previously mentioned genome copies to infectivity ratio.

The frequency of surface contamination was determined by the prevalence of the disease in the population ${ }^{49-53}$ and the frequency of contact with the surface. Two contact frequencies were used: high (every 1-20 min) and low (every 60-240 min). A cough was assumed to spread particles conically. ${ }^{54}$ Therefore, virus inoculation on hands was modeled as a function of the concentration of virus in the saliva, the volume of saliva expelled per cough, the distance between the mouth and the hand, and the right circular cone angle of the ejected particles ( $\alpha$ in Figure S2 and Table S1). Transfer from surfaceto-hand and from hand-to-mucous membranes was assumed proportional to the concentration of the virus on the surface and the transfer efficiency of the virus at both interfaces ${ }^{41}$ (Figure S1). The concentration of the virus on the contaminated surface was assumed to decay exponentially. ${ }^{55}$ The decay rate was obtained from research on SARS-CoV-2 survival on various surfaces. ${ }^{18}$ An exponential dose-response model $^{42}$ was used to estimate the probability of infection for a given dose. The concentration on the contaminated surface and on the hand was reduced according to the $\log _{10}$ reduction values for the scenarios of surface and hand disinfection. Alcohol-based hand sanitizer was selected as the hand disinfection strategy due to the widespread availability and portability of hand sanitizers. Although handwashing was not considered, based on the log reductions of enveloped viruses achieved by handwashing, ${ }^{56}$ we assume the effectiveness of handwashing is similar to that of hand sanitizer for the reduction of SARS-CoV-2 on hands.

Monte Carlo simulations were used to incorporate uncertainty and variability of the input parameters in the risk characterization. Convergence was tested for the baseline scenario by running five times 5,000, 10,000, 20,000, 50,000, and 100,000 simulations. There was minimal variation after 50,000 simulations (Figure S3). On the basis of the results, all the models were simulated 50,000 times. For each of the 50,000 simulations, the risks were calculated for a single contact of one surface followed by a hand-to-face contact, accounting for time-dependent variation in surface contamination (due to timing and frequency of contamination and exposure events). Therefore, each simulation has a time profile of contaminations for a period of 7 days and a profile of risks across time. The median, 25th, and 75th quartiles of the seven day simulations were recorded for each of the 50,000 simulations, and the average values of the median, 25th, and 75 th quartiles are reported (Figure 2). A sensitivity analysis 
was performed to investigate how the variability and uncertainty of the parameters in the model influenced the estimated risks. The sensitivity was estimated using the Spearman's correlation coefficients between the inputs and outputs of the model. A detailed description of the model and model parameters are found in the Supporting Information (Figure S1, Table S1).

\section{RESULTS AND DISCUSSION}

Risks from Contaminated Surfaces. Risks of SARSCoV-2 infection from contact with a fomite in community settings are estimated to be low (Figure 1) and influenced by

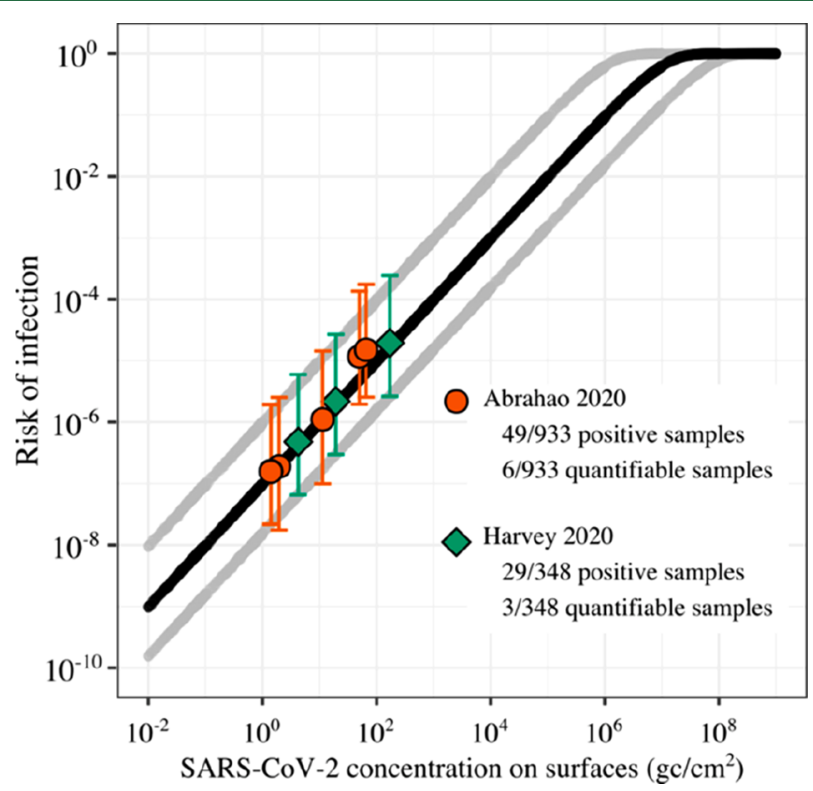

Figure 1. Risk of SARS-CoV-2 infection (unitless, from 0 to 1 ) as a function of virus concentration on surfaces (genome copies (gc)/ $\mathrm{cm}^{2}$ ). Median risk of infection is shown as a continuous black line, Gray lines display the 5th and 95th percentiles. Orange circles ${ }^{13}$ and green diamonds ${ }^{15}$ represent the median risk estimates for point values of surface contamination in public spaces, as reported for the subset of samples with detectable and quantifiable SARS-CoV-2 RNA in two studies, with whiskers from the 5th to 95th percentiles. Specifically, data from Abrahao et al. ${ }^{13}$, orange circles, shows the risk for the 6 quantifiable samples out the 933 sampled surfaces. Data from Harvey et al., ${ }^{15}$ green diamonds, shows the risk of 3 quantifiable samples out of the 348 sampled surfaces.

both the infection prevalence rate in the community and the frequency with which the fomite is contacted (Figure 2). The median risk of infection from a single surface-to-hand contact followed by hand-to-face contact with a contaminated fomite is linearly related to surface contamination, ranging from $10^{-9}$ for a surface with 0.01 RNA genome copies $(\mathrm{gc}) \mathrm{cm}^{-2}$ to approximately 1 for a surface with $\geq 10^{7} \mathrm{RNA} \mathrm{gc} \mathrm{cm}^{-2}$ (Figure $1)$. Previous studies of surface contamination on public spaces have detected from 0.1 to 102 SARS-CoV-2 $\mathrm{gc} \mathrm{cm}^{-2}{ }^{13,15}$ In the two studies, only 3 of 1281 ( $0.2 \%)$ surfaces sampled were associated with risks of infection greater than 1 in 100,000 . The average of the median risks of infection for all the sampled surfaces combined was of $4.1 \times 10^{-8}$, assuming negligible risks for samples with SARS-CoV-2 RNA below the LOD (1203 out of 1281 surfaces).

Risks from Surface-Mediated Community Transmission. When modeling risks of surface contamination within communities, the average median value (IQR) risks from a single hand-to-surface contact followed by hand-to-face contact range from approximately $1.6 \times 10^{-4}\left(2.0 \times 10^{-5}, 1.4\right.$ $\left.\times 10^{-3}\right)$ for the highest risk scenario (5\% infection prevalence rate, frequently touched surface $)$ to $5.6 \times 10^{-9}\left(7.4 \times 10^{-12}\right.$, $\left.1.6 \times 10^{-6}\right)$ for the lowest risk scenario $(0.2 \%$ prevalence rate, nonfrequently touched surface) (Figure 2). The overwhelming majority of interactions with fomites modeled were associated with risks less than $10^{-4}$ (Table S2). The low risks of community transmission of SARS-CoV-2 via fomites is in accordance with previous studies and opinions of fomitemediated transmission in hospitals. ${ }^{4-7}$

According to the sensitivity analysis, the model parameters mostly influencing the estimated infection risks within a community are transfer efficiency between the surface and the hand, $\mathrm{TE}_{\mathrm{sh}}$ and concentration of SARS-CoV-2 in sputum or saliva, $C_{\text {sp }}$ (Table S1, Figure S4). $\mathrm{TE}_{\mathrm{sh}}$ was inversely correlated with risk (Spearman's rank correlation, $\rho=-0.58$ ), and $C_{\mathrm{sp}}$ was directly correlated $(\rho=0.29)$. Correlation was low with all other modeled parameters $(\rho<0.05)$.

Effectiveness of Hand and Surface Disinfection. Hand hygiene was consistently the most effective intervention at reducing the risk of SARS-CoV-2 infection. Alcohol-based hand disinfectants are portable, widely available, and effective at inactivating coronavirus. ${ }^{57,58}$ Even with low compliance, representing only 1 in 4 people disinfecting hands after surface contact, median infection risks from fomite contact were reduced by $0.6-2.2 \log _{10}$. Under high compliance, representing 3 of every 4 people disinfecting, median risks decreased by 3.4-4.0 $\log _{10}$. Importantly, the impact of hand hygiene also appears to be independent of surface contact frequency and prevalence rates, suggesting a strategy of hand disinfection promotion in community settings is universally applicable. Our findings reaffirm the existing strategies of promoting hand hygiene and making hand disinfectant products widely available in shared community settings. ${ }^{59}$

Although the risks of SARS-CoV-2 transmission via fomites are estimated to be low under realistic community infection prevalence rates $(0.2 \%$ or $1 \%)$, they are possible and may contribute to a small number of new cases during outbreaks. Under the high prevalence rate scenario (5\%), the risks from fomites may become non-negligible. However, the risks from the dominant transmission routes (i.e., droplet-mediated transmission) would also likely increase. Although single touch risks are generally low, a person's infection risk increases when accounting for the dozens of objects contacted every hour and the thousands of frequently contacted objects within a city (crosswalk buttons, public transportation buttons, ATMs, and railings). Each interaction provides an opportunity for SARS-CoV-2 transmission. There is insufficient data on the number of times a person contacts surfaces in public spaces, limiting efforts to estimate daily risks. However, if we assume people contact 10 surfaces within a community per day and each surface has the same probability of infection risk, the daily risk for the baseline scenario ( $1 \%$ prevalence, frequently touched surfaces) would be $\sim 7 \times 10^{-6}$. Similarly, 100 contacts per day corresponds to a daily risk of $\sim 7 \times 10^{-5}$ or 7 in 100,000 .

The data used to quantify risks from measured concentrations of SARS-CoV-2 RNA on surfaces in public spaces were obtained from two locations: Somerville, Massachusetts, USA, ${ }^{15}$ and Belo Horizonte, Minas Gerais State, Brazil. ${ }^{13}$ The sampling collection for both studies occurred throughout a 


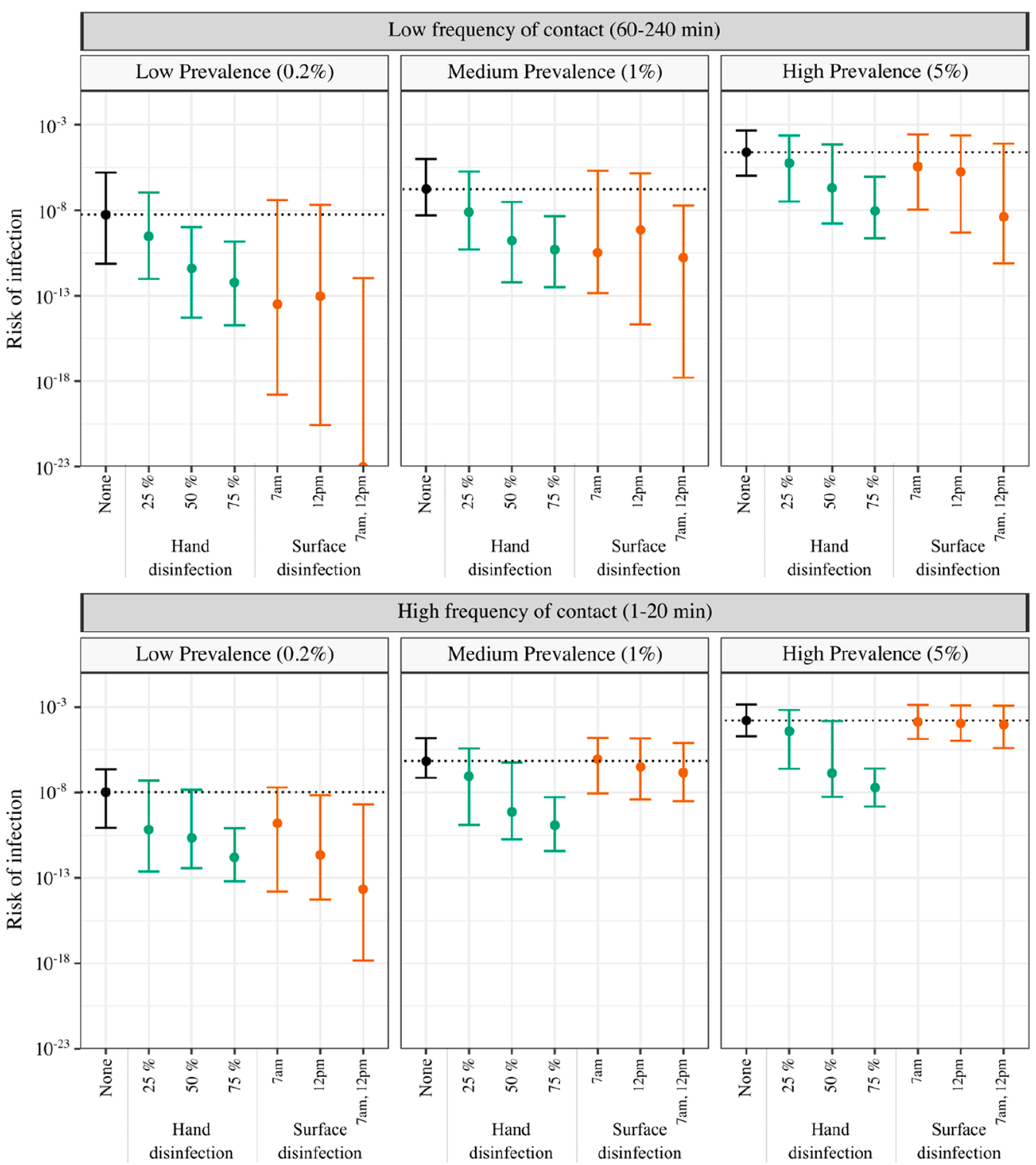

Figure 2. Predicted community-based risk of SARS-CoV-2 infection due to hand-to-surface contact followed by hand-to-face contact. The plot shows the average median risk of infection, with whiskers from the 25 th to the 75 th percentiles. Two interventions were tested [hand disinfection (green) and surface disinfection (orange)] in parallel to no intervention control (black). Compliance for hand disinfection was set to $25 \%$, $50 \%$, and $75 \%$ of the population. Surface disinfection regimes were every day at $7 \mathrm{am}, 12 \mathrm{pm}$, or $7 \mathrm{am}$ and $12 \mathrm{pm}$. The horizontal black dotted line illustrates the median risk of infection without intervention. Two contact frequencies and three prevalence levels (percentage of the population sick at any given time) were modeled: high contact frequency $(1-20 \mathrm{~min})$ and low contact frequency $(60-240 \mathrm{~min})$ and low $(0.2 \%)$, medium (1\%), and high $(5 \%)$ prevalence. The risk of infection of $10^{-6}$ is equivalent to one person sick as a result of hand-to-mouth contact for every million people touching the surface.

COVID-19 outbreak from March-June 2020. Both places had control measures when the collection took place, including mandatory use of masks in public spaces. The mask use requirement may have influenced surface contamination, with the measured SARS-CoV-2 RNA concentrations lower than what could be observed without a mask requirement. Our modeled interventions included hand disinfection and surface disinfection, but given the widespread use of masks within a community, masks may also help to curb fomite-mediated transmission. Masks are repeatedly shown to be effective at reducing transmission of SARS-CoV-2 ${ }^{60}$ through the proposed mechanism of limiting both production of and exposure to aerosolized droplets. Masks may also influence fomitemediated transmission by reducing hand or surface contamination from droplets and/or reducing hand-to-mouth contact frequency. As there is currently insufficient data on the effectiveness of masks against droplet production and on the frequency of hand-to-mouth contacts, mask use could not be considered as an intervention here.

The model findings are influenced by the model implementation and assumptions, and changes in assumptions may shift some of our conclusions. First, absolute infection risks from QMRA may be unreliable due to the uncertainty and/or variability in the estimates of the parameters. ${ }^{61}$ The exponential dose-response model in particular suffers from a number of limitations; the model is based on data of SARS$\mathrm{CoV}$ and Murine hepatitis virus (MHV-1) infection in mice by intranasal administration. ${ }^{43,44}$ Since the fraction of the infective virus that could enter the host through the mucous membranes via the fomite transmission route is smaller than through 
intranasal administration of the virus, the dose-response model used herein will likely overestimate the risks. In addition, extrapolating the model from mice to people and from MHV-1 and SARS-CoV to SARS-CoV-2 introduces uncertainty in infection risk estimates, but-in accordance with current best practice ${ }^{62}$ - we did not consider this here. Nevertheless, dose-response relationships derived from animal studies tend to be more conservative. ${ }^{63}$ An additional limitation is that the dose-response relationship was determined using the virus as measured in units of Plaque Forming Units (PFU), and therefore, a ratio of genome copies to PFU is needed. The assumed range of ratios from 1:100 to 1:1000 for genome copies to viable virus is based on Influenza, along with data on SARS-CoV and the sparse data currently available for SARS-CoV-2. Data quantifying the viable virus on fomites in communities would be the "gold standard", but detection of the viable virus is unlikely given that previously observed concentrations of SARS-CoV-2 RNA align with estimates of the viable virus of less than $1 / 100 \mathrm{~cm}^{2}$. Because of the uncertainties in parameter estimates, QMRA estimates of relative risk reduction from interventions are viewed as more reliable because potential biases in data are incorporated into both the intervention and control risk estimates. ${ }^{61}$

Additional model characteristics likely influence risk estimates. Model parameters used for virus transfer and decay rates are determined experimentally in laboratory conditions and could be different in environmental conditions. Also, prevalence rates modeled here are assumed to correspond directly with the percent of people who are infected and contact the surface with a hand contaminated by coughing. In reality, an unknown fraction of infected people would likely either (1) stay at home (i.e., quarantine and/or isolation) or (2) not cough directly on their hand. In this regard, the modeled infection risks are likely higher (more conservative) than would be expected at the stated community infection prevalence rates.

Despite the limitations of the underlying model, Quantitative Microbial Risk Assessment remains a valuable tool to understand and characterize risks of surface-mediated transmission of SARS-CoV-2 within communities and test the effectiveness of different interventions. Epidemiological investigations and/or structured experimental designs (i.e., randomized controlled trials) are infeasible given that fomitemediated transmission is likely a rare event and is difficult to decouple from other-more likely-transmission routes. The results presented here add to the evidence supporting the relatively low contribution of fomites in the transmission of SARS-CoV- $2^{15}$ and can inform guidance on potential intervention strategies.

\section{ASSOCIATED CONTENT}

\section{SI Supporting Information}

The Supporting Information is available free of charge at https://pubs.acs.org/doi/10.1021/acs.estlett.0c00966.

Diagram of the mathematical models used to estimate the risk. Distributions and input parameters used in the risk assessment models. Model for virus inoculation on hands. Plot of model convergence. Sensitivity analysis for the surface-mediated community transmission model. Table with percentage of contacts with estimated risks above $10^{-4}$. Plot of 10 simulations of virus concentrations and risks across time. (PDF)

\section{AUTHOR INFORMATION}

\section{Corresponding Author}

Ana K. Pitol - Department of Civil and Environmental Engineering, Imperial College London, London SW7 2AZ, United Kingdom; 이이이.org/0000-0002-7265-5677; Email: a.pitol-garcia@imperial.ac.uk

\section{Author}

Timothy R. Julian - Eawag, Swiss Federal Institute of Aquatic Science and Technology, Dübendorf CH-8600, Switzerland; Swiss Tropical and Public Health Institute, Basel CH-4051, Switzerland; University of Basel, Basel CH-4055,

Switzerland; @ orcid.org/0000-0003-1000-0306

Complete contact information is available at:

https://pubs.acs.org/10.1021/acs.estlett.0c00966

\section{Author Contributions}

T.R.J. and A.K.P designed the study. A.K.P. performed the modeling. T.R.J. and A.K.P wrote the manuscript.

\section{Notes}

A previous version of this paper was uploaded at Pitol AK, Julian TR, 2020. Community Transmission of SARS-CoV-2 by Fomites: Risks and Risk Reduction Strategies. medRxiv 2020.11.20.20220749. https://www.medrxiv.org/content/10. $1101 / 2020.11 .20 .20220749 v 1$ (accessed December 10, 2020). The code for the model can be accessed at https:// github.com/pitolana/QMRA SARS-CoV-2 Surfaces. The authors declare no competing financial interest.

\section{ACKNOWLEDGMENTS}

We thank Danilo Cuccato and Emmanuel Froustey for their inputs on the model; Amy Pickering, Abigail Harvey, and Erica Fuhrmeister for their inputs on the manuscript; and Diego Marcos, Sunil K. Dogga, Gabriele Micali, Esther Greenwood, Sital Uprety, and Elyse Stachler for reviewing the manuscript. Ana K. Pitol was supported by Swiss National Science Foundation - SNSF.

\section{REFERENCES}

(1) Centers for Disease Control (CDC). Scientic Brief: SARS-CoV-2 and Potential Airborne Transmission, 2020. https://www.cdc.gov/ coronavirus/2019-ncov/more/scientific-brief-sars-cov-2.html (accessed Oct 10, 2020).

(2) World Health Organization. Transmission of SARS-CoV-2: Implications for Infection Prevention Precautions, 2020. https://www. who.int/news-room/commentaries/detail/transmission-of-sars-cov-2implications-for-infection-prevention-precautions (accessed Oct 10, 2020).

(3) Ferretti, L.; Wymant, C.; Kendall, M.; Zhao, L.; Nurtay, A.; Abeler-Dörner, L.; Parker, M.; Bonsall, D.; Fraser, C. Quantifying SARS-CoV-2 transmission suggests epidemic control with digital contact tracing. Science 2020, 368, eabb6936-8.

(4) Goldman, E. Exaggerated risk of transmission of COVID-19 by fomites. Lancet Infect. Dis. 2020, 20, 892-893.

(5) Mondelli, M. U.; Colaneri, M.; Seminari, E. M.; Baldanti, F.; Bruno, R. Low risk of SARS-CoV-2 transmission by fomites in real-life conditions. Lancet Infect. Dis. 2020, 3099, 30678.

(6) Colaneri, M.; Seminari, E.; Piralla, A.; Zuccaro, V.; Di Filippo, A.; Baldanti, F.; Bruno, R.; Mondelli, M. U. Lack of SARS-CoV-2 RNA environmental contamination in a tertiary referral hospital for infectious diseases in Northern Italy. J. Hosp Infect 2020, 105, 474476.

(7) Colaneri, M.; Seminari, E.; Novati, S.; Asperges, E.; Biscarini, S.; Piralla, A.; Percivalle, E.; Cassaniti, I.; Baldanti, F.; Bruno, R.; 
Mondelli, M.U.; Bruno, R.; Mondelli, M.U.; Brunetti, E.; Di Matteo, A.; Seminari, E.; Maiocchi, L.; Zuccaro, V.; Pagnucco, L.; Ludovisi, S.; et al. Severe acute respiratory syndrome coronavirus 2 RNA contamination of inanimate surfaces and virus viability in a health care emergency unit. Clin. Microbiol. Infect. 2020, 26, 1094.e11094.e5.

(8) Boone, S. A.; Gerba, C. P. Significance of fomites in the spread of respiratory and enteric viral disease. Appl. Environ. Microbiol. 2007, 73, 1687-1696.

(9) Kraay, A. N. M.; Hayashi, M. A. L.; Hernandez-Ceron, N.; Spicknall, I. H.; Eisenberg, M. C.; Meza, R.; Eisenberg, J. N. S. Fomite-mediated transmission as a sufficient pathway: a comparative analysis across three viral pathogens. BMC Infect. Dis. 2018, 18, na DOI: $10.1186 / \mathrm{s} 12879-018-3425-\mathrm{x}$.

(10) Xiao, S.; Li, Y.; Wong, T.; Hui, D. S. C. Role of fomites in SARS transmission during the largest hospital outbreak in Hong Kong. PLoS One 2017, 12, e0181558.

(11) Ong, S. W. X.; Tan, Y. K.; Chia, P. Y.; Lee, T. H.; Ng, O. T.; Wong, M. S. Y.; Marimuthu, K. Air, Surface Environmental, and Personal Protective Equipment Contamination by Severe Acute Respiratory Syndrome Coronavirus 2 (SARS-CoV-2) from a Symptomatic Patient. JAMA - J. Am. Med. Assoc 2020, 323, 1610.

(12) Ye, G.; Lin, H.; Chen, S.; Wang, S.; Zeng, Z.; Wang, W.; Zhang, S.; Rebmann, T.; Li, Y.; Pan, Z.; Yang, Z.; Wang, Y.; Wang, F.; Qian, Z.; Wang, X. Environmental contamination of the SARS-CoV-2 in healthcare premises: An urgent call for protection for healthcare workers. J. Infect. 2020, 81, e1.

(13) Abrahao, J. S.; Sacchetto, L.; Rezende, I. M.; Rodrigues, R. A. L.; Crispim, A. P. C.; Moura, C.; Mendonca, D. C.; Reis, E.; Souza, F.; Oliveira, G. F. G.; Domingos, I.; de Miranda Boratto, P. V.; Silva, P. H. B.; Queiroz, V. F.; Machado, T. B.; Andrade, L. A. F.; Lourenco, K. L.; Silva, T.; Oliveira, G. P.; de Souza Alves, V.; et al. Detection of SARS-CoV-2 RNA on public surfaces in a densely populated urban area ofBrazil: A potential tool for monitoring the circulation of infected patients. Sci. Total Environ. 2020, 142645.

(14) Chia, P. Y.; Coleman, K. K.; Tan, Y. K.; Ong, S. W. X.; Gum, M.; Lau, S. K.; Lim, X. F.; Lim, A. S.; Sutjipto, S.; Lee, P. H.; Son, T. T.; Young, B. E.; Milton, D. K.; Gray, G. C.; Schuster, S.; Barkham, T.; De, P. P.; Vasoo, S.; Chan, M.; Ang, B. S. P.; et al. Detection of air and surface contamination by SARS-CoV-2 in hospital rooms of infected patients. Nat. Commun. 2020, 11, na DOI: 10.1038/s41467020-16670-2.

(15) Harvey, A. P.; Fuhrmeister, E. R.; Cantrell, M. E.; Pitol, A. K.; Swarthout, J. M.; Powers, J. E.; Nadimpalli, M. L.; Julian, T. R.; Pickering, A. J. Longitudinal Monitoring of SARS-CoV-2 RNA on High-Touch Surfaces in a Community Setting. Environ. Sci. Technol. Lett. 2020, na DOI: 10.1021/acs.estlett.0c00875.

(16) Riddell, S.; Goldie, S.; Hill, A.; Eagles, D.; Drew, T. W. The effect of temperature on persistence of SARS-CoV-2 on common surfaces. Virol. J. 2020, 17, 145.

(17) Chin, A.; Chu, J.; Perera, M.; Hui, K.; Yen, H.-L.; Chan, M.; Peiris, M.; Poon, L. Stability of SARS-CoV-2 in different environmental conditions. Lancet Microbe 2020, 1, e10.

(18) van Doremalen, N.; Bushmaker, T.; Morris, D. H.; Holbrook, M. G.; Gamble, A.; Williamson, B. N.; Tamin, A.; Harcourt, J. L.; Thornburg, N. J.; Gerber, S. I.; Lloyd-Smith, J. O.; de Wit, E.; Munster, V. J. Aerosol and Surface Stability of SARS-CoV-2 as Compared with SARS-CoV-1. N. Engl. J. Med. 2020, 382, 1564.

(19) Julian, T. R.; Leckie, J. O.; Boehm, A. B. Virus transfer between fingerpads and fomites. J. Appl. Microbiol. 2010, 109, 1868-1874.

(20) Lopez, G. U.; Gerba, C. P.; Tamimi, A. H.; Kitajima, M.; Maxwell, S. L.; Rose, J. B. Transfer efficiency of bacteria and viruses from porous and nonporous fomites to fingers under different relative humidity conditions. Appl. Environ. Microbiol. 2013, 79, 5728-5734.

(21) Rusin, P.; Maxwell, S.; Gerba, C. Comparative surface-to-hand and fingertip-to-mouth transfer efficiency of gram-positive bacteria, gram-negative bacteria, and phage. J. Appl. Microbiol. 2002, 93, 585592.
(22) Pitol, A. K.; Bischel, H.; Kohn, T.; Julian, T. R. Virus transfer at the skin-liquid interface. Environ. Sci. Technol. 2017, 51, 1441714425 .

(23) Lu, C.-w.; Liu, X.-f.; Jia, Z.-f. 2019-nCoV transmission through the ocular surface must not be ignored. Lancet 2020, 395, No. e39.

(24) Nicas, M.; Best, D. A study quantifying the hand-to-face contact rate and its potential application to predicting respiratory tract infection. J. Occup. Environ. Hyg. 2008, 5, 347-352.

(25) Kwok, Y. L. A.; Gralton, J.; McLaws, M. L. Face touching: A frequent habit that has implications for hand hygiene. Am. J. Infect. Control 2015, 43, 112-114.

(26) Lewis, R. C.; Rauschenberger, R.; Kalmes, R. Hand-to-mouth and other hand-to-face touching behavior in a quasi-naturalistic study under controlled conditions. J. Toxicol. Environ. Health, Part A 2020, $1-7$.

(27) Wilson, A. M.; Verhougstraete, M. P.; Beamer, P. I.; King, M. F.; Reynolds, K. A.; Gerba, C. P. Frequency of hand-to-head, -mouth, -eyes, and -nose contacts for adults and children during eating and non-eating macro-activities. J. Exposure Sci. Environ. Epidemiol. 2020, na DOI: $10.1038 / s 41370-020-0249-8$.

(28) Julian, T. R.; Canales, R a.; Leckie, J. O.; Boehm, A. B. A model of exposure to rotavirus from nondietary ingestion iterated by simulated intermittent contacts. Risk Anal 2009, 29, 617-632.

(29) Bischel, H. N.; Caduff, L.; Schindelholz, S.; Kohn, T.; Julian, T. R. Health Risks for Sanitation Service Workers along a ContainerBased Urine Collection System and Resource Recovery Value Chain. Environ. Sci. Technol. 2019, 53, 7055-7067.

(30) Canales, R. A.; Reynolds, K. A.; Wilson, A. M.; Fankem, S. L. M.; Weir, M. H.; Rose, J. B.; Abd-Elmaksoud, S.; Gerba, C. P. Modeling the role of fomites in a norovirus outbreak. J. Occup. Environ. Hyg. 2019, 16, 16-26.

(31) Adhikari, U.; Chabrelie, A.; Weir, M.; Boehnke, K.; McKenzie, E.; Ikner, L.; Wang, M.; Wang, Q.; Young, K.; Haas, C. N.; Rose, J.; Mitchell, J. A Case Study Evaluating the Risk of Infection from Middle Eastern Respiratory Syndrome Coronavirus (MERS-CoV) in a Hospital Setting Through Bioaerosols. Risk Anal 2019, 39, 26082624.

(32) King, M-F., Wilson, A. M., Weir, M. H., Lopez-Garcia, M., Proctor, J., Hiwar, W., Khan, A., Fletcher, L. A., Sleigh, P. A., Clifton, I., Dancer, S. J., Wilcox, M. H., Reynolds, K. A., Noakes, C. J. Modelling the risk of SARS-CoV-2 infection through PPE doffing in a hospital environment. medRxiv 2020.09.20.20197368. 2020, DOI: $10.1101 / 2020.09 .20 .20197368$.

(33) Jones, R. M. Relative contributions of transmission routes for COVID-19 among healthcare personnel providing patient care. $J$. Occup. Environ. Hyg. 2020, 17, 408.

(34) Wilson, A. M.; Abney, S. E.; King, M.-F.; Weir, M. H.; LopezGarcla, M.; Sexton, J. D.; Dancer, S. J.; Proctor, J.; Noakes, C. J.; Reynolds, K. A. COVID-19 and use of non-traditional masks: how do various materials compare in reducing the risk of infection for mask wearers? J. Hosp Infect 2020, 105, 640.

(35) Bullard, J.; Dust, K.; Funk, D.; Strong, J. E.; Alexander, D.; Garnett, L.; Boodman, C.; Bello, A.; Hedley, A.; Schiffman, Z.; Doan, K.; Bastien, N.; Li, Y.; Van Caeseele, P. G.; Poliquin, G. Predicting Infectious Severe Acute Respiratory Syndrome Coronavirus 2 From Diagnostic Samples. Clin. Infect. Dis. 2020, 71, 2663.

(36) Kim, J. Y.; Ko, J. H.; Kim, Y.; Kim, Y. J.; Kim, J. M.; Chung, Y. S.; Kim, H. M.; Han, M. G.; Kim, S. Y.; Chin, B. S. Viral load kinetics of SARS-CoV-2 infection in first two patients in Korea. J. Korean Med. Sci. 2020, 35, 1-7.

(37) Sampath, R.; Hofstadler, S. A.; Blyn, L. B.; Eshoo, M. W.; Hall, T. A.; Massire, C.; Levene, H. M.; Hannis, J. C.; Harrell, P. M.; Neuman, B.; Buchmeier, M. J.; Jiang, Y.; Ranken, R.; Drader, J. J.; Samant, V.; Griffey, R. H.; McNeil, J. A.; Crooke, S. T.; Ecker, D. J. Rapid identification of emerging pathogens: Coronavirus. Emerging Infect. Dis. 2005, 11, 373-379.

(38) Ip, D. K. M.; Lau, L. L. H.; Chan, K. H.; Fang, V. J.; Leung, G. M.; Peiris, M. J. S.; Cowling, B. J. The Dynamic Relationship between Clinical Symptomatology and Viral Shedding in Naturally Acquired 
Seasonal and Pandemic Influenza Virus Infections. Clin. Infect. Dis. 2015, 62, 431-437.

(39) Converting TCID50 to Plaque Forming Units PFU-12, ATCC, 2012. https://www.lgcstandards-atcc.org/Global/FAQs/4/8/ Converting_TCID50_to_plaque_forming_units_PFU-124. aspx?geo_country=gb (accessed Sep 20, 2020).

(40) Thompson, K. A.; Bennett, A. M. Persistence of influenza on surfaces. J. Hosp Infect 2017, 95, 194-199.

(41) Wilson, A. M.; King, M. F.; Lopez-Garciá, M.; Weir, M. H.; Sexton, J. D.; Canales, R. A.; Kostov, G. E.; Julian, T. R.; Noakes, C. J.; Reynolds, K. A. Evaluating a transfer gradient assumption in a fomite-mediated microbial transmission model using an experimental and Bayesian approach. J. R. Soc., Interface 2020, 17, 20200121.

(42) Watanabe, T.; Bartrand, T. A.; Weir, M. H.; Omura, T.; Haas, C. N. Development of a Dose-Response Model for SARS Coronavirus. Risk Anal. 2010, 30, 1129-1138.

(43) DeDiego, M. L.; Pewe, L.; Alvarez, E.; Rejas, M. T.; Perlman, S.; Enjuanes, L. Pathogenicity of severe acute respiratory coronavirus deletion mutants in hACE-2 transgenic mice. Virology 2008, 376, 379. (44) De Albuquerque, N.; Baig, E.; Ma, X.; Zhang, J.; He, W.; Rowe, A.; Habal, M.; Liu, M.; Shalev, I.; Downey, G. P.; Gorczynski, R.; Butany, J.; Leibowitz, J.; Weiss, S. R.; McGilvray, I. D.; Phillips, M. J.; Fish, E. N.; Levy, G. A. MurineHepatitis Virus Strain 1 Produces a Clinically Relevant Model of Severe Acute Respiratory Syndrome in A/J Mice. J. Virol. 2006, 80, 10382.

(45) Zhou, B.; Thao, T. T. N.; Hoffmann, D.; Taddeo, A.; Ebert, N.; Labroussaa, F.; Pohlmann, A.; King, J.; Portmann, J.; Halwe, N. J.; Ulrich, L.; Trüe, B. S.; Kelly, J. N.; Fan, X.; Hoffmann, B.; Steiner, S.; Wang, L.; Thomann, L.; Lin, X.; Stalder, H.; et al. SARS-CoV-2 spike D614G variant confers enhanced replication and transmissibility. bioRxiv, 2020, DOI: 10.1101/2020.10.27.357558.

(46) Wölfel, R.; Corman, V. M.; Guggemos, W.; Seilmaier, M.; Zange, S.; Müller, M. A.; Niemeyer, D.; Jones, T. C.; Vollmar, P.; Rothe, C.; Hoelscher, M.; Bleicker, T.; Brünink, S.; Schneider, J.; Ehmann, R.; Zwirglmaier, K.; Drosten, C.; Wendtner, C. Virological assessment of hospitalized patients with COVID-2019. Nature 2020, 581, 465-469.

(47) Pan, Y.; Zhang, D.; Yang, P.; Poon, L. L. M.; Wang, Q. Viral load of SARS-CoV-2 in clinical samples. Lancet Infect. Dis. 2020, 20, 411-412.

(48) To, K. K. W.; Tsang, O. T. Y.; Leung, W. S.; Tam, A. R.; Wu, T. C.; Lung, D. C.; Yip, C. C. Y.; Cai, J. P.; Chan, J. M. C.; Chik, T. S. H.; Lau, D. P. L.; Choi, C. Y. C.; Chen, L. L.; Chan, W. M.; Chan, K. H.; Ip, J. D.; Ng, A. C. K.; Poon, R. W. S.; Luo, C. T.; Cheng, V. C. C.; et al. Temporal profiles of viral load in posterior oropharyngeal saliva samples and serum antibody responses during infection by SARS-CoV-2: an observational cohort study. Lancet Infect. Dis. 2020, $20,565-574$.

(49) Bendavid, E.; Mulaney, B.; Sood, N.; Shah, S.; Ling, E.; Bromley-Dulfano, R.; Lai, C.; Weissberg, Z.; Saavedra, R.; Tedrow, J.; Tversky, D.; Bogan, A.; Kupiec, T.; Eichner, D.; Gupta, R.; Ioannidis, J.; Bhattacharya, J. COVID-19 Antibody Seroprevalence in Santa Clara County, California. medRxiv 2020.04.14.20062463, 2020, DOI: $10.1101 / 2020.04 .14 .20062463$.

(50) Perez-Saez, J.; Lauer, S. A; Kaiser, L.; Regard, S.; Delaporte, E.; Guessous, I.; Stringhini, S.; Azman, A. S; Alioucha, D.; Arm-Vernez, I.; Bahta, S.; Barbolini, J.; Baysson, H.; Butzberger, R.; Cattani, S.; Chappuis, F.; Chiovini, A.; Collombet, P.; Courvoisier, D.; De Ridder, D.; et al. Serology-informed estimates of SARS-CoV-2 infection fatality risk in Geneva, Switzerland. Lancet Infect. Dis. 2020, 3099, 23.

(51) Pollan, M.; Perez-Gomez, B.; Pastor-Barriuso, R.; Oteo, J.; Hernan, M. A; Perez-Olmeda, M.; Sanmartin, J. L; Fernandez-Garcia, A.; Cruz, I.; Fernandez de Larrea, N.; Molina, M.; Rodriguez-Cabrera, F.; Martin, M.; Merino-Amador, P.; Leon Paniagua, J.; MunozMontalvo, J. F; Blanco, F.; Yotti, R.; Blanco, F.; Gutierrez Fernandez, R.; et al. Prevalence of SARS-CoV-2 in Spain (ENE-COVID): a nationwide, population-based seroepidemiological study. Lancet 2020, $396,535-544$.
(52) Erikstrup, C.; Hother, C. E.; Pedersen, O. B. V.; Mølbak, K.; Skov, R. L.; Holm, D. K.; Sækmose, S. G.; Nilsson, A. C.; Brooks, P. T.; Boldsen, J. K.; Mikkelsen, C.; Gybel-Brask, M.; Sørensen, E.; Dinh, K. M.; Mikkelsen, S.; Møller, B. K.; Haunstrup, T.; Harritshøj, L.; Jensen, B. A.; Hjalgrim, H.; et al. Estimation of SARS-CoV-2 infection fatality rate by real-time antibody screening of blood donors. Clin. Infect. Dis. 2020, na DOI: $10.1093 / \mathrm{cid} /$ ciaa849.

(53) Amorim Filho, L.; Szwarcwald, C. L.; Mateos, S. d. O. G.; Ponce de Leon, A. C. M.; Medronho, R. d. A.; Veloso, V. G.; Lopes, J. I. F.; Porto, L. C. d. M. S.; Chieppe, A.; Werneck, G. L. Seroprevalence of anti-SARS-CoV-2 among blood donors in Rio de Janeiro, Brazil. Rev. Saude Publica 2020, 54, 69.

(54) Nicas, M.; Sun, G. An integrated model of infection risk in a health-care environment. Risk Anal 2006, 26, 1085-1096.

(55) van Doremalen, N.; Bushmaker, T.; Morris, D. H.; Holbrook, M. G.; Gamble, A.; Williamson, B. N.; Tamin, A.; Harcourt, J. L.; Thornburg, N. J.; Gerber, S. I.; Lloyd-Smith, J. O.; de Wit, E.; Munster, V. J. Aerosol and Surface Stability of SARS-CoV-2 as Compared with SARS-CoV-1. N. Engl. J. Med. 2020, 382, 1564.

(56) Kumar Chaudhary, N.; Chaudhary, N.; Dahal, M.; Guragain, B.; Rai, S.; Chaudhary, R.; Sachin, K. M.; Lamichhane-Khadka, R.; Bhattarai, A. Fighting the SARS CoV-2 (COVID-19) Pandemic with Soap. Preprints, 20202020050060.

(57) Rabenau, H. F.; Kampf, G.; Cinatl, J.; Doerr, H. W. Efficacy of various disinfectants against SARS coronavirus. J. Hosp Infect 2005, 61, 107-111.

(58) Golin, A. P.; Choi, D.; Ghahary, A. Hand sanitizers: A review of ingredients, mechanisms of action, modes of delivery, and efficacy against coronaviruses. Am. J. Infect. Control 2020, 48, 1062.

(59) World Health Organization (WHO). Recommendation to Member States to Improve Hand Hygiene Practices Widely to Help Prevent the Transmission of the COVID-19 Virus, Interim Guidance, 2020. https://www.who.int/publications/i/item/recommendationsto-member-states-to-improve-hand-hygiene-practices-to-help-preventthe-transmission-of-the-covid-19-virus (accessed Dec 2020).

(60) Liang, M.; Gao, L.; Cheng, C.; Zhou, Q.; Uy, J. P.; Heiner, K.; Sun, C. Efficacy of face mask in preventing respiratory virus transmission: A systematic review and meta-analysis. Travel Med. Infect Dis 2020, 36, 101751.

(61) World Health Organization (WHO). Quantitative Microbial Risk Assessment. Application for Water Safety Management, 2016. https://apps.who.int/iris/handle/10665/246195 (accessed Dec 2020).

(62) Haas, C. N., Rose, J. B., Gerba, C. P. Quantitative Microbial Risk Assessment, 2nd ed.; John Wiley \& Sons, Inc, 2014.

(63) Haas, C. WikiQMRA: Completed Dose Response Models. http:// qmrawiki.org/framework/dose-response/experiments (accessed Aug 2, 2020). 